\title{
Critical periods in the prenatal morphogenesis of the human lateral pterygoid muscle, the mandibular condyle, the articular disk, and medial articular capsule
}

\begin{abstract}
Ellen J. Van der Linden, D.D.S., ${ }^{*}$ Alphonse R. Burdi, Ph.D., ${ }^{* *}$ and Henry J. de Jongh, Prof.*** Ann Arbor, Mich., and Groningen, The Netherlands

This study was prompted by the renewed clinical interests in understanding the natural history or early morphogenesis of the human temporomandibular joint. Using histologic preparations of 52 representative human embryos and fetuses, each of the major components of the joint was systematicaliy assessed for its changing structure and related to an approximate time scale. The emergence and continued morphogenesis of the joint articular fossa, mandibular condyle, disk, capsule, lateral pterygoid muscle fibers, and both joint cavities occur in regular temporal and spatial pattern. A key observation from this study of embryos and fetuses ranging in age from 32 days to 22 weeks is that each of the component parts of the TMJ progressively emerge with some kind of continuity from a common mass of embryonic mesenchyme interposed between the future temporal bone and mandibular regions. The observations of this study lead to the suggestion that significant developmental disturbances to this common tissue mass or "developmental field" can lead to anomalous morphogenesis of those structures expected to emerge over time from the "developmental field" of the temporomandibular joint. Timing and the identification of a critical time period for the joint are important variables. This study identifies the critical period in the early morphogenesis of TMJ structures as generally falling between the early 7 th and 11 th prenatal weeks. (Am J Orthod Dentofac Orthop 1987;91:22-8.)
\end{abstract}

Key words: Prenatal, temporomandibular joint, human, critical periods, timing, developmental fields

$\mathrm{W}_{\mathrm{it}}$ ith increasing interest in the natural history, clinical delineation, and management of such craniofacial anomalies as hemifacial microsomia and mandibulofacial dysostosis, there has been a renewed interest in the chronology and early morphogenesis of the human temporomandibular joint (TMJ) and its component parts. The call for more details on time-linked patterns of early TMJ development has arisen especially from an interesting report of prenatal mandibulofacial dysostosis that showed that the typical features seen in this condition were already manifested in the second trimester.

This report focuses on the chronology and structural changes during the early morphogenic periods of the

*Visiting Scholar. Department of Anatomy and Cell Biology, and Center for Human Growth and Development, University of Michigan.

**Department of Anatomy and Cell Biology, and Center for Human Growth and Development, University of Michigan

***Director, Department of Anatomy and Embryology, University of Groningen, The Netherlands. temporomandibular joint. The report has certainly been advantaged by the availability of existing detailed studies $^{2-s}$ that have taken us well beyond the static and almost uniform picture of TMJ development seen in classical textbooks of human embryology. Specific questions on the emergence of TMJ musculoskeletal relationships have not escaped investigation. It is known, for example, that the uppermost fibers of the adult lateral pterygoid muscle attach to the TMJ articular disk. Yet, it is still unclear as to when and how such attachments first occur in the life history of the joint. Studies have shown such fibers attaching variously to the disk, condyle, and articular capsule., ${ }^{2,6-10}$ The variations among these studies may well be explained by fundamental differences in the ages of the study samples - that is, embryos, fetuses, and adults.

It is the general purpose of this study then to provide a focused picture on the chronology of morphogenic changes in early human TMJ structures, including the important considerations of musculoskeletal attachments. 
Table I. Summary of TMJ morphologic staging plan

\begin{tabular}{|c|c|c|}
\hline$T M J$ component & Stage & Appearance \\
\hline \multirow{5}{*}{$\begin{array}{l}\text { Temporal bone } \\
\text { articular } \\
\text { fossa }\end{array}$} & 0 & $\begin{array}{l}\text { No signs of tissue organiza- } \\
\text { tion }\end{array}$ \\
\hline & 2 & $\begin{array}{l}\text { Appearance of condensed } \\
\text { mesenchyme }\end{array}$ \\
\hline & 4 & Initial signs of osseous matrix \\
\hline & 6 & Trabecular formation \\
\hline & 8 & $\begin{array}{l}\text { Presence of primary cancel- } \\
\text { lous bone }\end{array}$ \\
\hline \multirow[t]{2}{*}{$\begin{array}{l}\text { Mandibular } \\
\text { condyle }\end{array}$} & $0-8$ & $\begin{array}{l}\text { Same as those for articular } \\
\text { fossa } \\
\text { plus }\end{array}$ \\
\hline & 10 & $\begin{array}{l}\text { Appearance of definitive con- } \\
\text { dylar cartilage }\end{array}$ \\
\hline \multirow{5}{*}{$\begin{array}{l}\text { Lateral pterygoid } \\
\text { muscle fibers }\end{array}$} & 0 & No signs of organization \\
\hline & 2 & $\begin{array}{l}\text { Mesenchymal condensations } \\
\text { in region }\end{array}$ \\
\hline & 4 & Appearance of myofibrils \\
\hline & 6 & $\begin{array}{l}\text { Appearance of muscle fiber } \\
\text { formation }\end{array}$ \\
\hline & 8 & $\begin{array}{l}\text { Presence of definite muscle } \\
\text { mass }\end{array}$ \\
\hline \multirow[t]{4}{*}{ Articular disk } & 0 & No signs of organization \\
\hline & 2 & $\begin{array}{l}\text { Condensed deeper staining } \\
\text { mesenchymal cells }\end{array}$ \\
\hline & 4 & Early signs of disk fibers \\
\hline & 6 & $\begin{array}{l}\text { Presence of definitive disk } \\
\text { mass }\end{array}$ \\
\hline \multirow[t]{3}{*}{$\begin{array}{l}\text { Upper and lower } \\
\text { cavities' }\end{array}$} & 0 & $\begin{array}{l}\text { No signs of cavity spaces in } \\
\text { mesenchymal block }\end{array}$ \\
\hline & 2 & $\begin{array}{l}\text { Cavity present extending and } \\
\text { conforming to about half of } \\
\text { condyle size }\end{array}$ \\
\hline & 4 & $\begin{array}{l}\text { Cavity size conforming fully } \\
\text { to condyle size }\end{array}$ \\
\hline \multirow[t]{4}{*}{ Articular capsule } & 0 & No signs of organization \\
\hline & 2 & $\begin{array}{l}\text { Signs of condensed and } \\
\text { deeper staining mesen- } \\
\text { chyme }\end{array}$ \\
\hline & 4 & $\begin{array}{l}\text { Organization of capsule tissue } \\
\text { fibers }\end{array}$ \\
\hline & 6 & $\begin{array}{l}\text { Appearance of definitive cap- } \\
\text { sule structure }\end{array}$ \\
\hline
\end{tabular}

${ }^{\mathrm{t}}$ Shapes of articular fossa, mandibular condyle, and cavities recorded as either concave, straight or convex.

${ }^{2}$ Fiber attachments to condyle, disk, and capsule were recorded as $(+)$ observable or $(-)$ not observable.

\section{MATERIALS AND METHODS}

Fifty-two human embryos and fetuses were randomly chosen for this study on the basis of the absence of gross physical abnormalities. Thus, this sample,

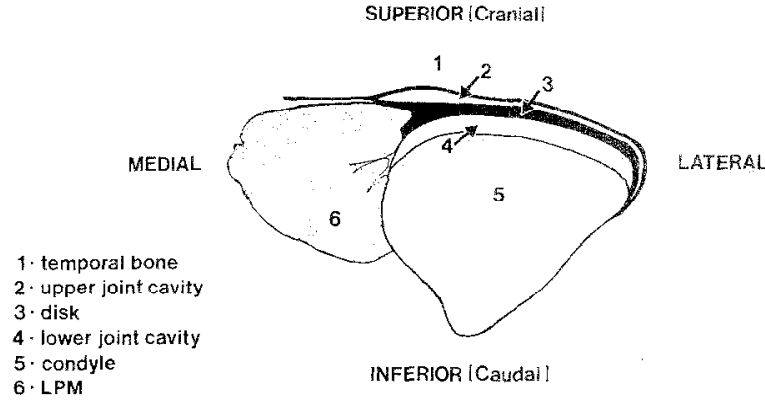

Fig. 1. Schema showing temporomandibular joint components (frontally sectioned) that are clearly definable at 21 to 22 prenatal weeks (203 mm CRL).

drawn from the University of Michigan Embryology Research Collection, included specimens that were typical-for-age or "normal" according to Patten. "The sample had a size range from 9 to $203 \mathrm{~mm}$ crown rump length (CRL) and an age range from 33 days to 22 weeks fertilization age. Formalin-fixed heads were prepared histologically and sectioned at $10 \mu \mathrm{m}$ in the frontal plane. Serial sections were stained with a routine Mallory trichrome connective tissue stain. This group of legally donated abortuses possessed temporomandibular joints from their earliest beginnings seen at the resolution of the light microscope to stages of near completion, wherein the component parts of the definitive temporomandibular joint were recognizable.

A straightforward morphologic staging plan was designed, tested, and finally used to help quantitate as much as possible the observations of histologic changes seen in the component parts of the temporomandibular joint. The assessment of histologic changes in tissues as mesenchyme, cartilage, bone, and muscle followed the descriptions of Patten ${ }^{11}$ and Ham and Cormack. ${ }^{12}$ The description of the staging plan used is shown in Table I.

\section{OBSERVATIONS}

Patterns of light microscopic changes and staging on the early morphogenesis of TMJ component parts (Figs. 1 through 4) are presented with an emphasis on the chronology of developmental changes (Figs. 5 through 7.)

The first appearance of the temporal bone articular fossa occurs at approximately 7 to 7.5 weeks $(21 \mathrm{~mm}$ CRL) as a visible condensation of deeper staining stellate cells comprising the embryonic mesenchyme. Spicules of primary cancellous bone appear most prominently at 10 to 11 weeks ( $60 \mathrm{~mm} \mathrm{CRL)}$. The shape of the articular fossa is initially convex during the first weeks of its development up to 9 weeks ( $40 \mathrm{~mm}$ CRL). 


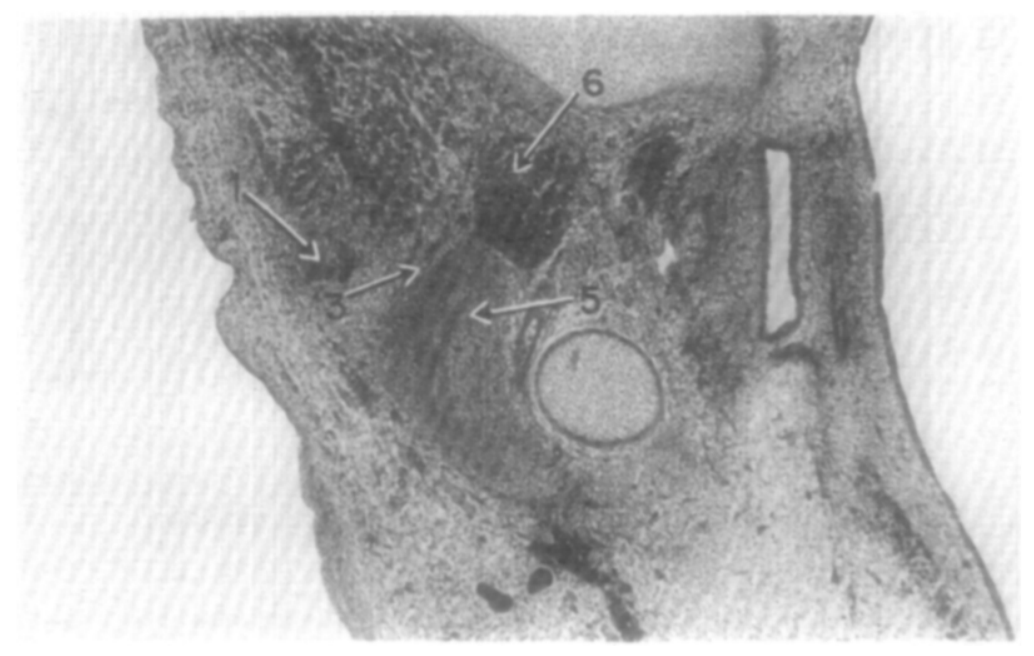

Fig. 2. Photomicrograph showing the early condensation of the TMJ articular disk (3) within the larger mesenchymal tissue field limited above by the temporal bone (1) and below by the mandibular condyle (5). Note the early attachment of the lateral pterygoid muscle (6) to the condyle. Frontal section through the TMJ area of a 47 -day human fetus $(29 \mathrm{~mm} \mathrm{CRL}$ ). (Original magnification $\times 40$.)

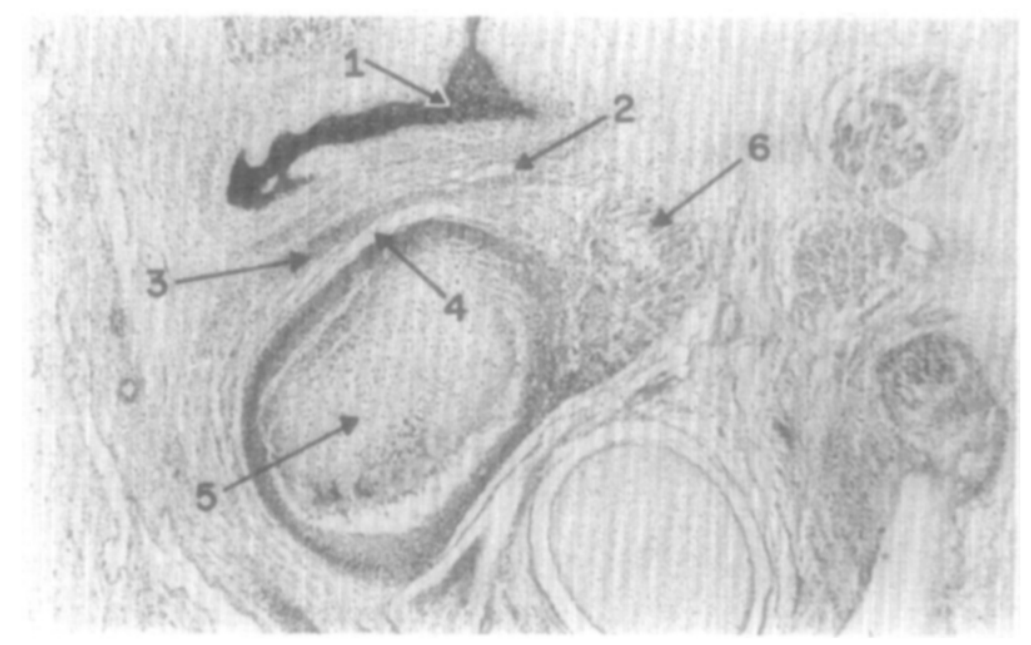

Fig. 3. Frontal section through TMJ region showing the early beginnings of cavitation of the lower (4) and upper joint (2) cavities on either side of the articular disk (3). The condyle (5) and articular region of the temporal bone (1) are clearly defined. Section is from a 10 to 11 week fetus (60 $\mathrm{mm} \mathrm{CRL}$ ). (Original magnification $\times 40$.)

After that time, the fossa progressively takes on its definitive concave shape, which matches the shape of the condylar head.

The beginning signs of mesenchymal condensation and shaping of the mandibular condyle occur at about the same time as for the articular fossa. This mass is superiorly convex. Condylar cartilage cells first appear between 9 and 10 weeks ( $40 \mathrm{~mm}$ to $50 \mathrm{~mm} \mathrm{CRL}$ ). The shape of this early cartilaginous condyle is that of the mesenchymal mass from which it arose. With few exceptions, it is convex. From this time on to the 10 th week, the ossification of the condyle and articular fossa are synchronous. When a difference in ossification is observed, it is the temporal bone that is more advanced. After the 10th week, the continuing ossification of the articular fossa appears more advanced in terms of increased cortical thickness and density of bony trabeculae. Up to about 10 weeks, the ossifying masses of the articular fossa and mandibular condyle are separated by a continuous and unseparated block of dense staining mesenchyme.

The first signs in the development of the lateral 
pterygoid muscle appear at 32 to 34 days when there is a very slight condensation of deeper staining mesenchyme near the medial portions of the whole mesenchymal block, which eventually gives rise to the several component parts of the joint as seen in this study. Definitive myofibrils are seen in the expected regions of the adult lateral pterygoid muscle and these early definitive fibers appear to be continuous with the presumptive disk region of the larger mesenchymal block. From 18 to 19 weeks on ( $165 \mathrm{~mm} \mathrm{CRL})$, the lateral pterygoid muscle fibers, and specifically those in the upper sphenomeniscus portion, are in their final stages of early morphogenesis (stages 6 and 8 ). From about 7 weeks on, the lower fibers of the muscle can be seen to attach to the neck region of the mandible.

The first appearance of the articular disk is typically seen at 7 to 7.5 weeks ( $21 \mathrm{~mm} \mathrm{CRL}$ ) as a deeper staining horizontal zone of mesenchyme running transversely within the block of tissue separating the articular fossa and condylar elements. Although there is some variation in this pattern, most specimens did show a definite mesenchymal zone in the area of the future articular disk by 8.5 weeks. Notably, this disk primordium consisting of deeply staining mesenchymal cells appears before clear-cut signs of cavitation for the upper and lower joint cavities. Early signs of collagenous disk fibers (stage 4) are seen by 10 to 10.5 weeks $(55 \mathrm{~mm}$ CRL) and progressively become more pronounced by approximately 12 weeks ( $75 \mathrm{~mm} \mathrm{CRL}$ ). From about 19 to 20 weeks on (178 $\mathrm{mm} \mathrm{CRL}$ ), the disk progressively takes on its fully formed fibrous structure (stage 6). The newly formed disk appears thinner in its more central region, which appears to be devoid of blood vessels seen at the periphery of the disk.

As with the articular disk, there is general variation with regards to timing and early initiation in development of the articular capsule during the time of generalized mesenchymal thickening around the presumptive joint area. The capsule first appears at approximately 9 to 11 weeks ( 40 to $60 \mathrm{~mm}$ CRL) as a very thin and deeply stained zone around the periphery of the early mesenchymal block, which eventually gives rise to the various TMJ components. Only in one specimen was the mesenchymal indication of the articular capsule seen earlier - that is, at 7 to 8 weeks. At about 17 weeks ( $150 \mathrm{~mm} \mathrm{CRL}$ ), the articular capsule is seen as a fully formed (stage 6) fibrous tissue boundary between the intracapsular and extracapsular components of the joint. Lateral pterygoid muscle fibers insert into the thickened medial portion of the capsule (that is, medial articular capsule) by that time.

The upper and lower joint cavities progressively appear as a group of small spaces or clefts within the

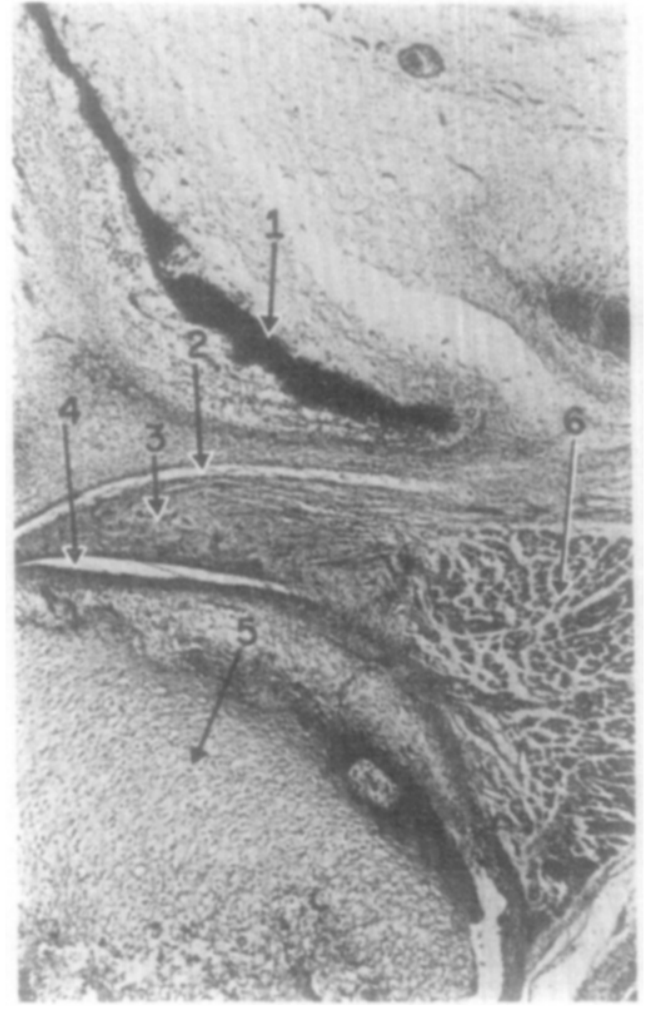

Fig. 4. Photomicrograph showing the attachmenis of the lateral pterygoid muscle (6) to the condyle (5) and articular disk (3). The upper (2) and lower (4) joint cavities are well defined on either side of the articular disk. Section shown is a frontal section through fetus of 15 weeks (119 mm CRL). (Original magniflcation $\times 40$.)

mesenchymal tissue block that had earlier given rise to the articular fossa, disk, and condyle. Initiation of both joint cavities is not synchronous. Small, coalescing clefts for the lower joint cavity appear at about 10 weeks ( 50 to $58 \mathrm{~mm} \mathrm{CRL}$ ), whereas those for the upper cavity are first seen at about 11.5 weeks ( 60 to $70 \mathrm{~mm} \mathrm{CRL}$ ). These small spaces or clefts between the mesenchymal cells in the area gradually enlarge and coalesce into larger spaces or cavities superior and inferior to the disk. When there is only one joint cavity that is present up to about 11.5 weeks, it is usually that of the lower cavity. From 11.5 weeks on, there is no marked difference between the upper and lower joint cavity formations in terms of structure, size, and timing. Both cavities are fully formed (stage 4) by that time and then increase in size to match the sizes of the articular fossa and mandibular condyle. By 17.5 weeks $(148 \mathrm{~mm}$ CRL), both cavities are present and fully match the sizes and shapes of the fossa and condyle. The shapes of the upper and lower joint cavities are generally reciprocal. When the upper joint cavity is concave, the lower cavity is convex. The lower joint cavity is al- 


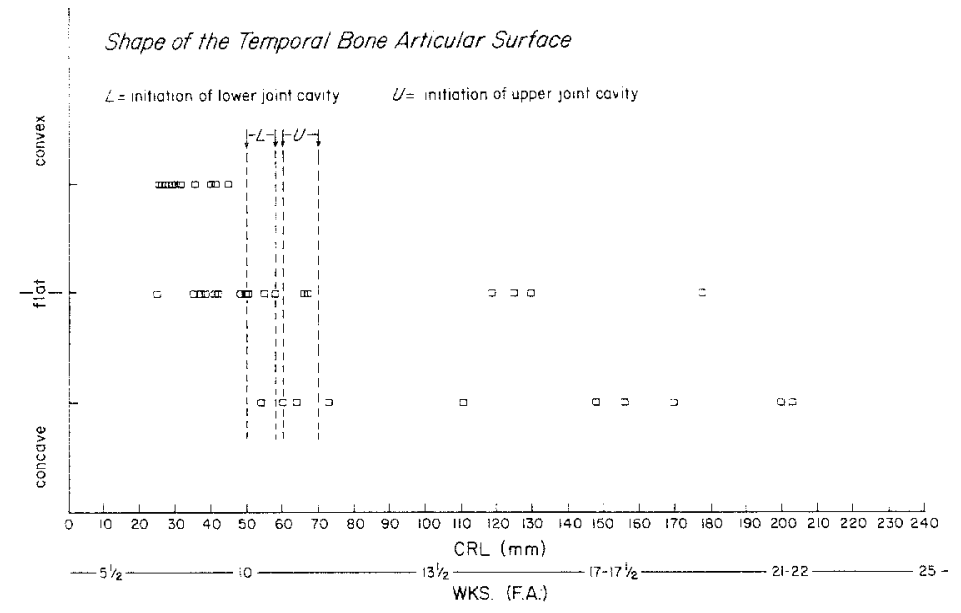

Fig. 5. Graph depicting shape changes of temporal bone articular fossa where contour of fossa moves from convex or flat appearance to its typical concave appearance. The timing of initiation of upper $(U)$ and lower $(L)$ joint cavities is shown.

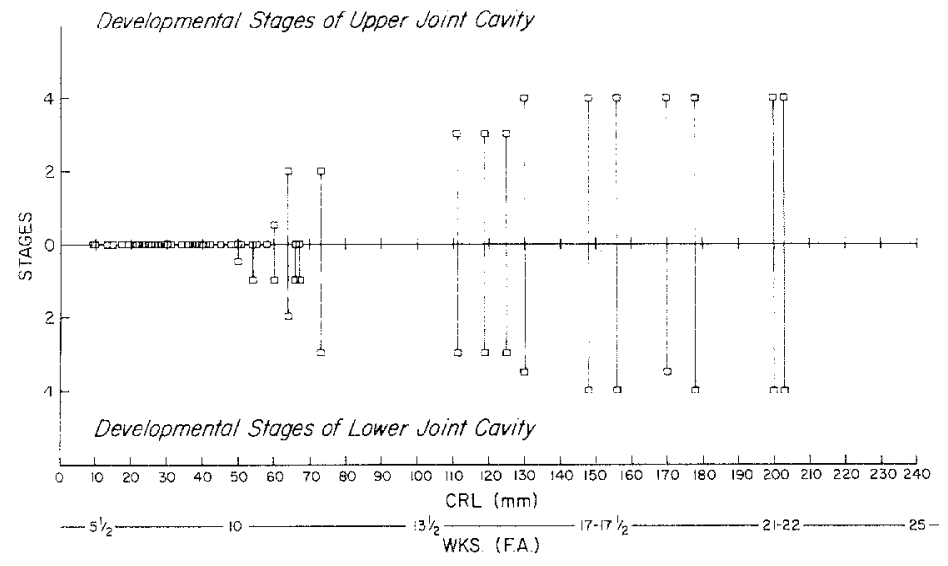

Fig. 6. Graph depicting developmental changes of upper and lower joint cavities. Note that presence of both cavities begins at about 10 weeks, after which the early cavities enlarge to their fullest size in the study. Staging values: $0=$ no cavitation; $2=50 \%$ cavitation; and $4=$ full cavitation.

most always convex, matching the shape of the articular condyle.

\section{DISCUSSION}

The observations of this study on the early morphogenesis of the human temporomandibular joint build upon and corroborate many of the earlier descriptions of Moffet, ${ }^{2}$ Furstman, ${ }^{3,4}$ and Perry. ${ }^{5}$ Important with this study is the focus on the chronology in development of the TMJ component parts (Figs. 5 through 7). In general, the observations made should give further emphasis to the view that morphogenesis, like growth, can be a patterned phenomenon.

A key observation of this study is that the early TMJ structures emerge progressively from a block of embryonic mesenchymal cells interposed between the developing temporal bone and mandible. As pointed out by Spyropoulos ${ }^{13}$ in an earlier study (1977) on the developing relations of the temporalis muscle with the coronoid process of the mandible, this early block of mesenchymal tissue is a "developmental field" whose normal morphogenesis into discrete anatomic parts can be interfered with in some significant and timely manner resulting in the anomalous development of one or more structures evolving from that "developmental ficld."

With this in mind, this study may help explain the chronology or timetable in the appearance of those anomalous TMJ components reported by Behrents, McNamara, and Avery in $1977^{1}$ for a prenatal case of mandibulofacial dysostosis. Contrary to Furstman ${ }^{4}$ who essentially showed the critical time in TMJ formation to be between the 8 th and the late 12 th prenatal weeks, 
observations in this study show the critical period to be somewhat earlier, from about early 7 to 11 weeks. Of course, when dealing with human abortuses in crosssectional studies, one has to keep in mind that observed times are at best approximate times. Nevertheless, it is this critical period of 7 to 11 weeks during which stages in the morphogenesis of the TMJ can be most sensitive to developmental insults, given that the important TMJ mesenchymal cells are differentiated and in place before the critical period.

The concept of a temporomandibular "developmental field" can be extended into the consideration of specific development of individual TMJ components. For example, the articular disk and joint capsule develop from the central and peripheral portions of the TMJ field, respectively. The medial portion of the capsule, for example, is a medial continuation of the central portion of the TMJ field, which gives rise to the disk. This helps explain then the mechanisms of attachment of the disk to the medial articular capsule regions seen in the definitive adult joint, that is, the capsule and disk developed from their earliest beginnings as a "developmental unit." This study of 52 human embryos and fetuses shows a third component in this "developmental unit." Fibers of the lateral pterygoid muscle also emerge from the larger "developmental field" for the temporomandibular joint, and the structural continuity of the muscle fibers, disk, and capsule are identifiable carly in the cmbryonic period when each of these three structures is undergoing its peak period of morphogenesis. Although Moffet ${ }^{2}$ reported seeing muscle fibers attaching only to the articular disk, this study's "developmental field" approach did show lateral pterygoid fibers connecting with the condylar neck as well. Thus, significant developmental disturbances (teratogens, for example) introduced before or during critical periods and at appropriate dosage levels ${ }^{14}$ can alter the normal development of either whole "developmental fields" or "developmental units within the field."

Given this chronology on the early morphogenesis of the human temporomandibular joint and related lateral pterygoid muscle, it is interesting to briefly speculate here on how the observations of this study relate to the understanding of prenatal mouth-opening reflexes (Fig. 7). Humphrey, ${ }^{15}$ continuing the work of Hooker, ${ }^{16}$ showed that active mouth opening in live human fetuses could be seen as early as 7 to 8 weeks, or about 26 $\mathrm{mm}$ in the present study. The present study shows that by that time only myofibrils of the lateral pterygoid muscle (stage 3) are present and the articular fossa, mandibular condyle, and disk are only in their earliest of morphogenic stages at best. In other words, the prenatal jaw activity that Hooker observed, even as prim-

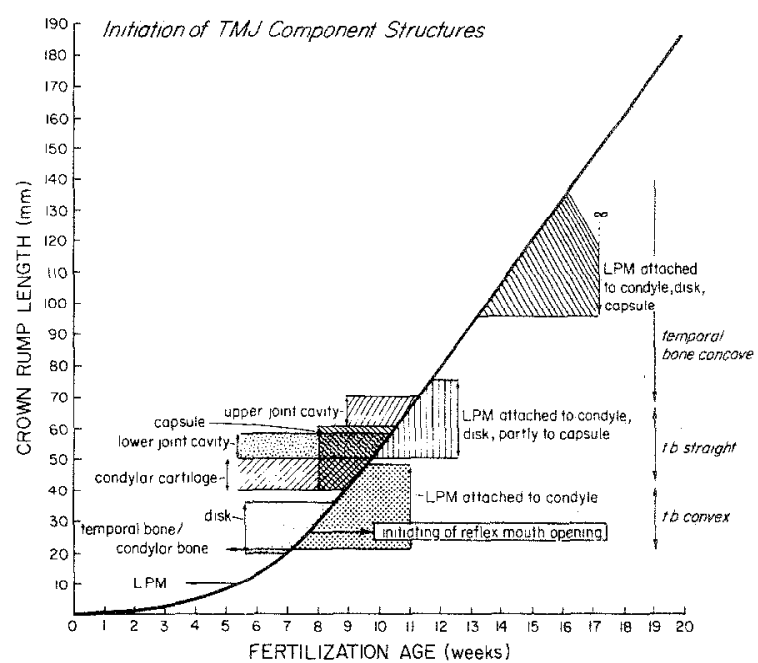

Fig. 7. Graph summarizing the sequential appearance of temporomandibular joint structures and regions demonstrating the approximate critical period for early TMJ morphogenesis falling between early 7 weeks through 11 weeks. Also shown is the time of mouth-opening reflexes roported by Humphrey and Hooker. ${ }^{15,16}$

itive reflexes, appeared unlikely to have involved definitive structures of the actual temporomandibular joint. This would suggest that the early jaw-opening movements reported by both Humphrey and Hooker probably involved the articulations of the primary temporomandibular joint, including the upper end of Mcckel's cartilage and the malleus and incus ear ossicles.

\section{CONCLUSIONS}

Based on the observations of this study, the critical period in the early prenatal morphogenesis of the human temporomandibular joint is an approximate time of early 7 to 11 weeks of fertilization age. There appears to be a definite pattern or sequence in the early shaping of each component of the temporomandibular joint relative to structure and chronology. Although this study does show specific morphogenic changes for the TMU on a structure-by-structure basis, it advances the concept of a "developmental field" from which closely related structures arise during development. That concept is extended even further in that groups of structures can arise from relatively large "developmental fields" as "developmental units." Such is the case of the muscle-disk-capsule "unit" emerging from the larger "developmental field" of the temporomandibular joint. This view of developmental fields and units may help explain certain craniofacial anomalies, such as mandibulofacial dysostosis in which defects involving the jaws are manifested in "developmental fields and units." 
This research was supported in part by NIH Grant DE $03610-19$.

\section{REFERENCES}

1. Behrents RG, McNamara JA, Avery JK. Prenatal mandibulofacial dysostosis (Treacher Collins syndrome). Cleft Palate J 1977; 14:13-34.

2. Moffett BC Jr. The prenatal development of the human temporomandibular joint. Carnegie Institute of Washington, Publ 611 , Contr Embryol 1957;36:19-28.

3. Furstman L. The early development of the human temporomandibular joint. AM J ORTHOD 1963;49:672-82.

4. Furstman L. Embryology. In: Sarnat BS, Laskin DM, eds. The temporomandibular joint. ed 3. Springfield, Illinois: Charles C Thomas, 1980.

5. Perry HT, Yinghua X, Forbes DP. The embryology of the temporomandibular joint. J Craniomandibular Pract 1985;3:125-32.

6. Rees $\mathrm{L} \Lambda$. The structure and function of the mandibular joint. $\mathrm{Br}$ Dent I 1954;96:125-33.

7. Choukas NC, Sicher H. The structure of the temporomandibular joint. Oral Surg Oral Med Oral Pathol 1960;13:1203-13.

8. Troiano MF. New concept of the insertion of the lateral pterygoid muscle. I Oral Surg 1967;25:337-40.

9. Honee $\mathrm{G}$. The anatomy of the lateral pterygoid muscle. Acta Morphol Neerl Scand 1972;10:331-40.
10. Pinkert R. Untersuchungen zum anatomischen Aufbau des Kiefergelenkes und zur Bewegung seiner Gewebe bei der Mundoffnung. Stomatologie der DDR 1980;30:744-50.

11. Patten BM. Human embryology. ed 3. New York: McGraw-Hill, 1968.

12. Ham AW, Cormack DH. Histology, ed 8. Philadelphia: JB Lippincott Company, 1979.

13. Spyropoulos MN. The morphogenetic relationship of the temporal muscle to the coronoid process in human embryos and fetuses. Am J Anat 1977;150:395-410.

14. Wilson IG. Environment and hith defects. New York: Academic Press, 1973.

15. Humphrey $T$. The development of mouth opening and related reflexes involving the oral area of human feruses. Ala I Med Sci $1968 ; 5: 126-57$.

16. Hooker D. Early human fetal activity, with a preliminary note on double simultaneous fetal stimulation. Res Publ Assoc Res Nerv Ment Dis 1954;33:98-113.

Reprint requests to:

Dr. A. R. Burdi

Department of Anatomy and Cell Biology

5811-15 Medical Science Bldg. II

The University of Michigan

Ann Arbor, MI 48109 